\title{
N36, a Synthetic N-Terminal Heptad Repeat Domain of the HIV-1 Envelope Protein gp41, Is an Activator of Human Phagocytes ${ }^{1}$
}

\author{
Yingying Le,* Shibo J iang, † J inyue Hu,* Wanghua Gong,‡ Shaobo Su,* Nancy M. Dunlop,* \\ Weiping Shen,* Baoqun Li, $\neq$ and J i Ming Wang*,2 \\ *Laboratory of Molecular Immunoregulation, Division of Basic Sciences and ¥I ntramural Research Support Program, SAIC Frederick, \\ National Cancer Institute-Frederick Cancer Research and Development Center, Frederick, Maryland 21702; \\ and HLindsley F. Kimball Research Institute, New York Blood Center, New York, New York 10021
}

Human immunodeficiency virus type 1 (HIV-1) envelope protein gp41 mediates viral fusion with human host cells. In this study we show that N36, a synthetic peptide derived from the $\mathrm{N}$-terminus of gp41, induced directional migration and calcium mobilization in human monocytes and neutrophils. The activity of N36 on phagocytes was pertussis toxin sensitive, suggesting involvement of a Gi-coupled seven-transmembrane receptor(s). Since high concentrations of the bacterial chemotactic peptide fMet-Leu-Phe (fMLF) partially desensitized the calcium mobilizing activity of N36 in phagocytes, we postulated that N36 might use a low-affinity fMLF receptor. By using cells stably expressing fMLF receptor FPR or FPRL1, we demonstrate that N36 uses FPRL1 as a functional receptor. Our results suggest that HIV-1 gp41 may contain a fragment(s) that activates the innate host immune cells through FPRL1. Since the activation of FPRL1 in monocytes has been shown to heterologously desensitize chemokine receptors, the reduced phagocyte response to chemoattractants seen in AIDS patients may be attributed, at least in part, to heterologous desensitization. $\odot 2000$ Academic Press

Key Words: N36 peptide; HIV-1 gp 41; chemoattractant receptor; phagocyte.

\section{INTRODUCTION}

Human immunodeficiency virus (HIV) uses envelope glycoproteins to enter cells. The envel ope glycoprotein complex consists of the surface subunit gp120 and the

\footnotetext{
${ }^{1}$ The content of this publication does not necessarily reflect the views or policies of the Department of Health and Human Services, nor does mention of trade names, commercial products, or organizations imply endorsement by the U.S. Government. The U.S. Government's right to retain a nonexclusive, royalty-free license in and to the copyright covering this paper, for governmental purposes, is acknowledged.

${ }^{2}$ To whom correspondence should be addressed at LMI, DBS, $\mathrm{NCl}-\mathrm{FCRDC}$, Building 560, Room 31-40, Frederick, MD 21702. Fax: (301) 846-7042. E-mail: wangji@mail.ncifcrf.gov.
}

transmembrane subunit gp41, which are produced through proteolytic cleavage of the precursor gp160. gp120 binds to CD4 and one of several coreceptors that are members of the chemokine receptor family. Subsequently, gp41 undergoes conformational changes that facilitate fusion of viral and host cell membranes (reviewed in Refs. 1, 2). The ectodomain of gp41 contains a glycine-rich $\mathrm{N}$-terminal sequence, named the fusion peptide, that is essential for membrane fusion (Fig. 1). The fusion peptide region is followed by two 4-3 hydrophobic (heptad) repeat regions predicted to form coiled-coils. The $\mathrm{N}$-terminal heptad repeat region is located adjacent to the fusion peptide, while the Cterminal heptad repeat region precedes the transmembrane segment (Fig. 1). Synthetic peptides derived from the $\mathrm{N}$ - and $\mathrm{C}$-terminal heptad repeat regions, designated the $\mathrm{N}$ and $\mathrm{C}$ peptides, respectively, are effective inhibitors of HIV infection and syncytia formation (3-5). The anti-HIV type 1 (HIV-1) activity of these peptides is proposed to be due to their competitive association with the corresponding segments on gp41, thus blocking the fusion between the viral and the cellular membranes.

Limited proteolysis of a recombinant fragment corresponding to the gp41 ectodomain generated a trimeric, $\alpha$-helical complex composed of two peptides, designated $\mathrm{N} 51$ and $\mathrm{C} 43$, that are derived from the $\mathrm{N}$ - and C-terminal heptad repeat regions (6). By further protein dissection, a subdomain within gp41 composed of the N 36 and C34 peptides was identified (7). This complex is believed to represent the core of fusion-active gp41 (8-10).

We have investigated the mechanistic basis for HIV1-associated suppression of monocyte function and found that preexposure of human monocytes to either HIV-1 envel ope proteins gp120 or gp41 inhibited their chemotactic response to a wide variety of chemoattractants, including the bacterial chemotactic peptide $\mathrm{N}$ formyl-methionyl-leucyl-phenylalanine (fMLF) and a number of chemokines, through a mechanism resembling heterologous "desensitization" $(11,12)$. The inac- 


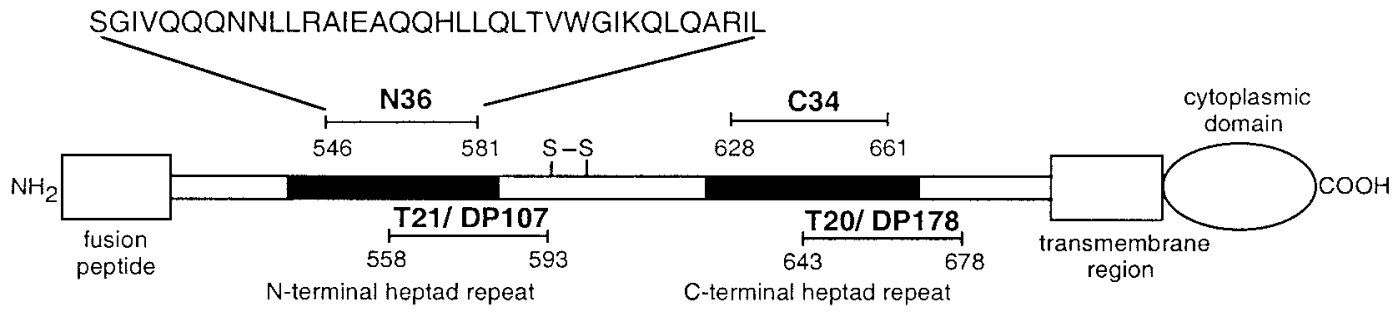

FIG. 1. Schematic representation of gp41. $\mathrm{N}$ and $\mathrm{C}$ peptides derived from the $\mathrm{N}$ - and C-terminal heptad repeat regions are indicated. The residues are numbered according to their positions in gp160 (Ref. 8).

tivation of monocytic chemotactic responses by HIV-1 envelope proteins may be responsible for the reduced migratory response of monocytes from AIDS patients to various chemoattractants in vitro (13). In order to define the structural basis for the capacity of HIV-1 envel ope proteins to "desensitize" host cells, we evaluated the effects of selected peptide segments of gp41 on human immune cells. We initially found that a synthetic C peptide, T20/DP178 (Fig. 1), was a potent chemoattractant and activator of human phagocytic leukocytes. The effect of T20/DP178 was mediated by FPR, a seven-transmembrane, G-protein-coupled receptor originally identified as the receptor for bacterial chemotactic formyl peptides (14-16). On the other hand, the synthetic N-terminal domain of gp41, T21/ DP107 (Fig. 1), activated human phagocytes by using both FPR and a FPR variant, FPRL 1, as its functional receptors (17). Since N 36 and C34 regions have been implicated as key structures for conversion of gp41 to the fusogenic conformation (8-10) and they overlap with T21/DP107 and T20/DP178 segments (Fig. 1, and Refs. 5-7), we determined whether these peptide domains had any potential to interact with human immune cells. Here we report that N 36 induces the directional migration and activation of human phagocytic cells by preferentially stimulating the receptor FPRL 1 .

\section{MATERIALS AND METHODS}

Reagents and Cells

N36 peptide, SGIVQQQN N LLRAIEAQQHLLQLTVWGIKQLQARIL, which corresponds to amino acid residues 546-581 in the $\mathrm{N}$-terminal heptad repeat region of HIV-1 gp41, was synthesized by a standard solidphase FMOC method in the New York Blood Center in-house facility. The $\mathrm{N}$-terminus of the peptide was uncapped and its C-terminus was amidated. The peptide was purified to homogeneity by high-performance liquid chromatography. The identity of the purified peptides was confirmed by laser desorption mass spectrometery (PerSeptive Biosystems). The endotoxin levels in dissolved peptide were undetectable by Limulus amebocyte lysate assays (sensitivity $0.06 \mathrm{IU} / \mathrm{ml}$; Bio-
Whittaker). Several other peptides from HIV-1 gp41, including fusion peptide (FP, aa 512-527), C34 (aa 628-661, a kind gift from Dr. P. S. Kim, Massachusetts Institute of Technology, Cambridge, MA), and recombinant N36(L6)C34, a stable subdomain consisting of N36 and C34, connected by a six-residue hydrophilic linker (a kind gift from Dr. M. Lu, Cornell University Medical College, New York, NY), were also tested for their biological effects. The synthetic chemotactic peptide fMLF was purchased from Sigma (St. Louis, MO). Recombinant human serum amyloid $A$ (rhSAA) and chemokines were purchased from PeproTech Inc. (Rocky Hill, NJ ). Human peripheral blood monocytes were isolated from Buffy Coats (NIH Clinical Center, Transfusion Medicine Department, Bethesda, MD) enriched for mononuclear cells by using an iso-osmotic Percoll gradient. Neutrophils were isolated from Buffy Coat blood with dextran sedimentation. The purity of the cell preparations was examined by morphology and was $>90 \%$ for monocytes and $>98 \%$ for neutrophils. Rat basophilic leukemia cells (RBL$2 \mathrm{H} 3$ ) transfected with epitope-tagged FPR (designated ETFR) were a kind gift from Drs. H. Ali and R. Snyderman (Duke University, Durham, NC). FPRL1transfected HEK/293 cells (designated FPRL1/293) were a kind gift from Drs. Philip M. Murphy and J iliang Gao (NIH, Bethesda, MD). All the transfected cells were maintained in DMEM supplemented with 10\% FBS (Hyclone, Logan, UT), 1 mM glutamine (Gibco BRL, Grand Island, NY), and $800 \mu \mathrm{g} / \mathrm{ml}$ geneticin (G418, Gibco BRL).

\section{Chemotaxis and Calcium Mobilization Assays}

Chemotaxis assays were performed using 48-well chemotaxis chambers (Neuro Probe, Cabin J ohn, MD) as described previously $(14,17)$. The results were expressed as the chemotaxis index, which represents the fold increase in the number of migrating cells in three high-powered fields in response to chemoattractants over the spontaneous cell migration in response to control medium. $\mathrm{Ca}^{2+}$ mobilization was measured by incubating $2 \times 10^{7}$ cells $/ \mathrm{ml}$ in loading medium 
A

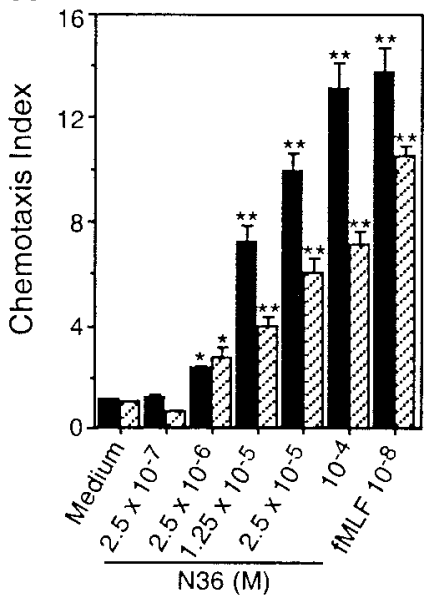

B

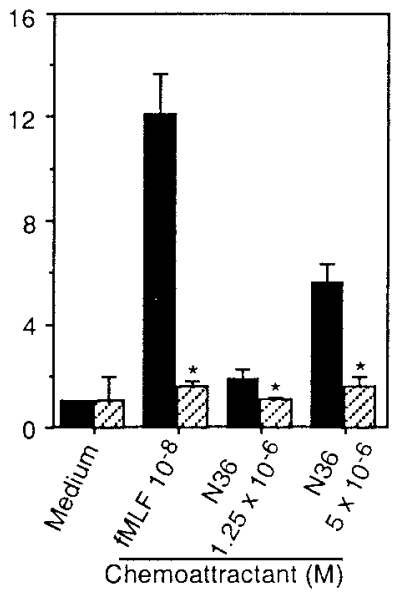

FIG. 2. Chemotactic activity of $N 36$ peptide for monocytes and neutrophils. (A) Fold increase (chemotaxis index) of phagocyte migration in response to N36 peptide over control medium (black histogram, monocytes; hatched histogram, neutrophils). *P $<0.05$, $* * P<0.01$, compared with spontaneous migration. (B) Inhibition of monocyte migration in response to $\mathrm{N} 36$ peptide by pertussis toxin (black histogram, cells were incubated with medium; hatched histogram, cells were preincubated with $100 \mathrm{ng} / \mathrm{ml}$ pertussis toxin at $37^{\circ} \mathrm{C}$ for $30 \mathrm{~min}$, washed, and examined for migration induced by different concentrations of $\mathrm{N} 36$ peptide). $* \mathrm{P}<0.01$ compared with migration of cells incubated with medium alone. fMLF was used as a control.

(DMEM , 10\% FBS, 2 mM glutamine) with $5 \mu$ M Fura-2 AM (Molecular Probes, Eugene, OR) for $30 \mathrm{~min}$ at room temperature. The dye-loaded cells were washed and resuspended in saline buffer $(138 \mathrm{mM} \mathrm{NaCl}, 6 \mathrm{mM}$ $\mathrm{KCl}, 1 \mathrm{mM} \mathrm{CaCl} 2,10 \mathrm{mM}$ Hepes (pH 7.4), $5 \mathrm{mM}$ glucose, $0.1 \%$ BSA) or HBSS at a density of $1 \times 10^{6} / \mathrm{ml}$. The cells were then transferred into quartz cuvettes (1-2 $210^{6}$ cells in $2 \mathrm{ml}$ ) that were placed in a luminescence spectrometer (LS-50B, Perkin-EImer, Beaconsfield, England). Stimulants at different concentrations were added in a volume of $20 \mu$ l to each cuvette at the indicated time points. The ratio of fluorescence at 340 and $380 \mathrm{~nm}$ was calculated using a FL WinLab program (Perkin-EImer).

\section{Statistical Analysis}

All experiments were performed at least three times and the results presented are from representative experiments. The significance of the difference between test and control groups was analyzed with Student's $t$ test.

\section{RESULTS}

We first tested whether synthetic N36, FP, and C34 and the recombinant N36(L 6)C34 could induce human leukocyte migration, a crucial step for cell homing and

accumulation at sites of inflammation or injury. While FP, C34, and N36(L6)C34 did not induce significant migration and calcium mobilization in human peripheral blood monocytes and neutrophils (data not shown), both these cell types migrated in a dose-dependent manner in response to a concentration gradient of N36 (Fig. 2A). Checkerboard analyses showed that monocytes migrated when higher concentrations of N36 were present in the lower wells of the chemotaxis chamber (Table 1). Cell migration was not enhanced when higher concentrations of N36 were present in the upper wells or equal concentrations of N36 were in both upper and lower wells. These results suggest that the effect of N36 on monocyte migration was chemotactic rather than chemokinetic. The migration of monocytes to N36 was completely inhibited by pretreatment of the cells with pertussis toxin (Fig. 2B), suggesting that a receptor coupled to a Gi-type $G$ protein $(15,16,18)$ was involved in cell activation by $N 36$. This hypothesis was supported by the induction of a dose-dependent and pertussis toxin-sensitive $\mathrm{Ca}^{2+}$ mobilization in monocytes and neutrophils with N36 (Figs. 3A and 3C; and data not shown).

To define the receptor(s) possibly used by N36 on phagocytic cells, a series of cross-desensitization experiments was performed by using a variety of chemoattractants. N36 did not desensitize the $\mathrm{Ca}^{2+}$ flux in monocytes or neutrophils induced by chemokines such as monocyte chemoattractant protein-1, regulated on activation normal T-cell expressed and secreted, monocyte chemoattractant protein-3, macrophage inflammatory protein-1 $\alpha$, interleukin 8 , and stromal cell-

TABLE 1

Checkerboard Analysis of Monocyte Migration in Response to N36 Peptide ${ }^{a}$

Number of migrated cells in $1 \mathrm{HPF}$ (mean \pm SE)

N36 peptide in upper wells (M)

lower wells (M) Medium $1.25 \times 10^{-6} \quad 5.00 \times 10^{-6} \quad 1.25 \times 10^{-5}$

\begin{tabular}{lrrrr} 
Medium & $8 \pm 2$ & $7 \pm 1$ & $3 \pm 1$ & $3 \pm 1$ \\
$1.25 \times 10^{-6}$ & $18 \pm 2^{\mathrm{b}}$ & $5 \pm 1$ & $2 \pm 1$ & $2 \pm 1$ \\
$5.00 \times 10^{-6}$ & $56 \pm 10^{\mathrm{b}}$ & $28 \pm 6^{\mathrm{b}}$ & $6 \pm 1$ & $5 \pm 1$ \\
$1.25 \times 10^{-5}$ & $78 \pm 8^{\mathrm{b}}$ & $36 \pm 6^{\mathrm{b}}$ & $25 \pm 4^{\mathrm{b}}$ & $10 \pm 2$ \\
\hline
\end{tabular}

${ }^{a}$ Different concentrations of N36 peptide were placed in the upper and/or lower wells of the chemotaxis chamber; monocytes at $2 \times$ $10^{6} / \mathrm{ml}$ were placed in the upper wells. The upper and lower wells were separated by a polycarbonate filter. After incubation, the nonmigrating cells were removed, the filter was fixed and stained, and the cells that migrated across the filter were counted in three highpowered fields (HPF, 400×). The results are expressed as the mean value $( \pm S E)$ of the cells in 1 HPF. Similar results were obtained for neutrophils in two separate experiments.

${ }^{\mathrm{b}} \mathrm{P}<0.01$ compared with migration in the presence of medium alone in both upper and lower wells as determined by Student's $t$ test. 
A

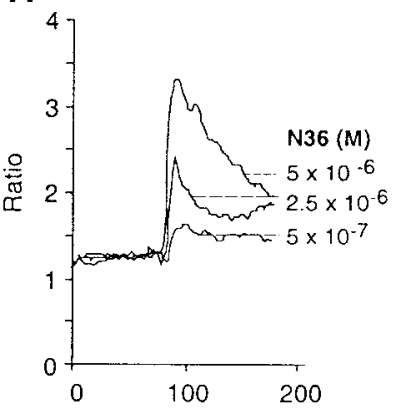

C

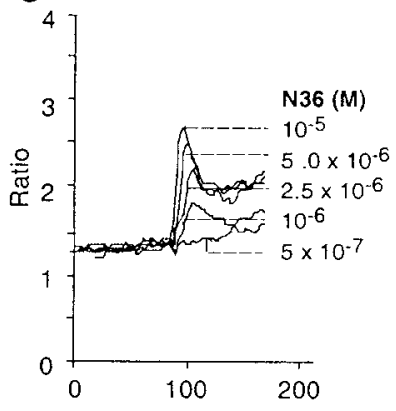

B

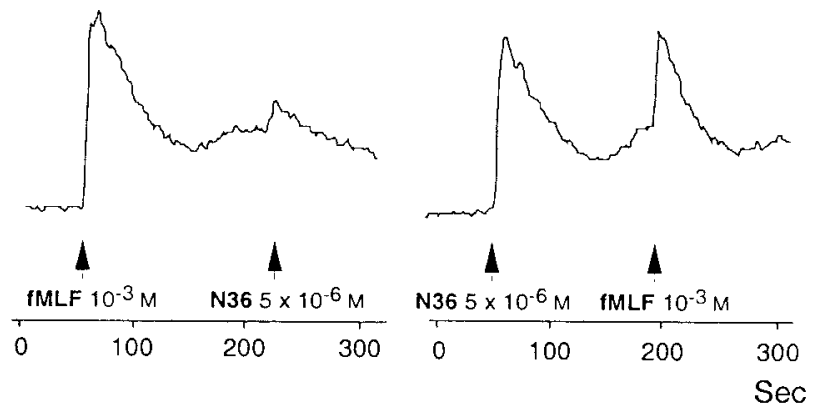

D

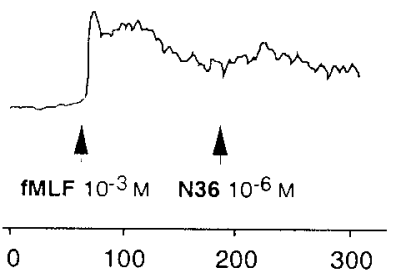

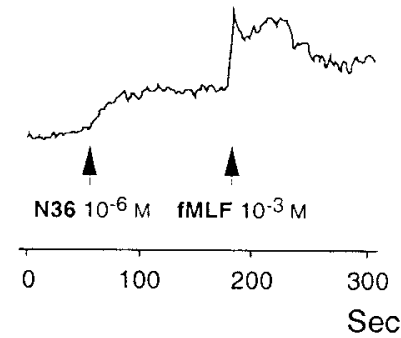

FIG. 3. Calcium mobilization induced by N36 peptide in phagocytes and attenuation by fMLF. Cells were loaded with Fura-2 and stimulated with different concentrations of N36 peptide or sequentially stimulated with fMLF and N36 peptide or vice versa (A and B, neutrophils; C and D, monocytes).

derived factor-1 $\alpha$ (data not shown). Therefore, N36 does not share a receptor with any of these chemokines. However, a high concentration $\left(10^{-3} \mathrm{M}\right)$ of the bacterial chemotactic $\mathrm{N}$-formylated peptide fMLF had a significant desensitizing effect on N36-induced $\mathrm{Ca}^{2+}$ mobilization in both monocytes and neutrophils (Figs. 3B and 3D). In contrast, N 36 only weakly desensitized the effect of $\mathrm{fMLF}$ (Figs. 3B and 3D). These results suggest that on human phagocytic cells N36 and fMLF may share a receptor that has low affinity for $\mathrm{AMLF}$.

Two G protein-coupled seven-transmembrane receptors that can be activated by fMLF have been identified: the high-affinity receptor FPR and its variant F PRL $1(15,16)$. We tested the signaling of N36 peptide on cells transfected with CDNAs coding either FPR (designated ETFR cell) or FPRL1 (designated FPRL 1/ 293 cell). FPRL 1/293 cells, but not ETFR cells or mocktransfected 293 cells, were responsive to N36 peptide in both chemotaxis (Fig. 4A; and data not shown) and $\mathrm{Ca}^{2+}$ mobilization experiments (Figs. 5A and 5B; and data not shown). As observed in monocytes, the migration of FPRL 1/293 cells induced by N36 was also inhibited by pretreatment of the cells with pertussis toxin (Fig. 4B). In addition, while the $\mathrm{Ca}^{2+}$ mobilization induced by N36 peptide in F PRL1/293 cells was attenuated by high concentrations of fMLF, N36 peptide conversely attenuated $\mathrm{fMLF}$-induced $\mathrm{Ca}^{2+}$ mobilization in these cells (Fig. 5C). The concentrations of N36 peptide required to activate $F P R L 1 / 293$ cells were in the low micromolar range, comparable to those for phagocyte activation. These results indicate that N36 peptide uses FPRL 1 as a functional receptor. We recently identified FPRL 1 to be a functional receptor for a normal human serum protein, serum amyloid A (SAA) (19), which increases its concentration by up to several hundredfold during acute-phase responses and is a potent phagocyte chemoattractant and activator $(20,21)$. Therefore we tested the cross-desensitization of $\mathrm{Ca}^{2+}$ flux in monocytes and FPRL1/293 cells between N36 and SAA to further confirm the usage of FPRL 1 by N36. SAA and N36 attenuated each other's $\mathrm{Ca}^{2+}$ mobilizing activity in both monocytes and FPRL 1/293 cells (Figs. 5D and 5E), indicating that these two chemoattractants share FPRL 1 as their functional receptor. It should be noted that N36 does not bear any significant sequence homology to either fMLF or SAA. Therefore, FPRL 1 is capable of reacting with a broad spectrum of ligands, a characteristic feature also reported for the prototype receptor FPR $(15,16)$.

\section{DISCUSSION}

FPRL 1 was identified and molecularly cloned a number of years ago, it possesses $69 \%$ identity to F PR at the 

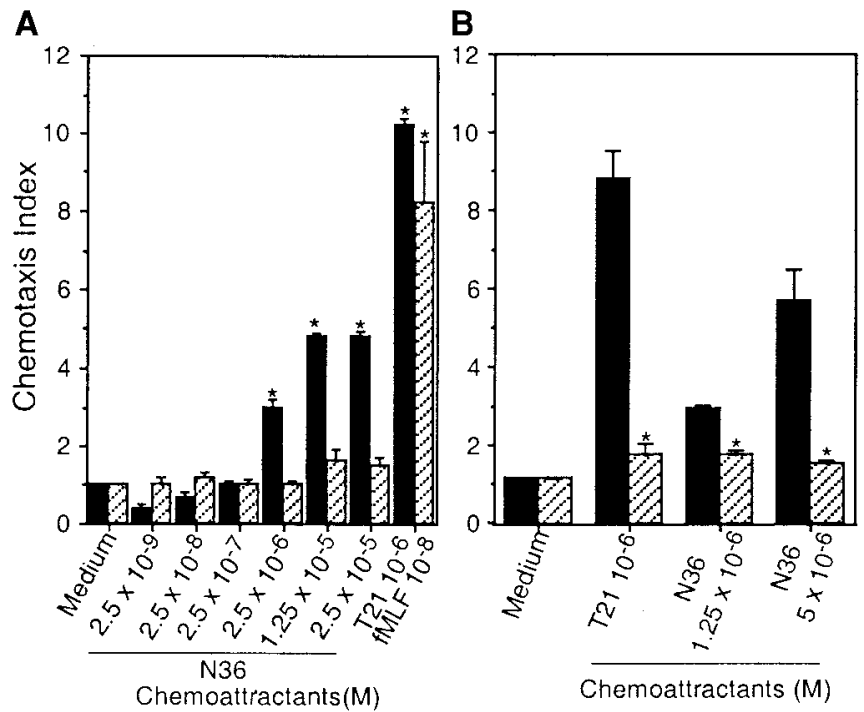

FI G. 4. Chemotactic activity of $N 36$ peptide for $F P R L 1 / 293$ cells. (A) Fold increase (chemotaxis index) of FRPL1/293 cell migration (black histogram) or ETFR cell migration (hatched histogram) in response to N36 peptide over control medium. T21/DP 107 and fMLF were used as control. (B) Inhibition of FPRL 1/293 cell migration in response to $\mathrm{N} 36$ peptide by pertussis toxin (black histogram, cells were incubated with medium; hatched histogram, cells were preincubated with $100 \mathrm{ng} / \mathrm{ml}$ pertussis toxin at $37^{\circ} \mathrm{C}$ for $30 \mathrm{~min}$, washed, and examined for migration induced by different concentrations of N36 peptide). $* \mathrm{P}<0.01$ compared with migration of cells incubated with medium alone. T21 was used as control.

amino acid level $(15,16)$. Both receptors are expressed by monocytes and neutrophils and are clustered on human chromosome 19q13. While fMLF is a high-affinity agonist for FPR, it interacts with and induces $\mathrm{Ca}^{2+}$ flux in FPRL1 only at high concentrations. Furthermore, $\mathrm{fMLF}$ did not induce significant migration of FPRL 1/293 cells at a concentration as high as $50 \mu \mathrm{M}$ $(17,19)$, suggesting that fMLF is not a full agonist for FPRL 1. In contrast, N36 induces migration of FPRL 1/ 293 cells at low micromolar concentrations. Thus, compared to fMLF, N36 is a functionally more relevant agonist for FPRL1. Although the signal transduction pathways mediated by FPRL 1 have not been extensively studied, the high level of homology to FPR, sensitivity to pertussis toxin, and mediation of potent phagocyte migration and activation by its agonists suggest that FPRL 1 shares many features of second-messenger activation with other G-protein-coupled chemoattractant receptors. In our previous study, incubation of human phagocytes with the FPRL 1 agonist SAA resulted in a reduction of cell response to a number of chemoattractants (21), suggesting that activation of FPRL 1 also initiates signaling events that desensitize other G-protein-coupled chemotactic receptors. In support of this hypothesis, we recently identified a peptide domain derived from HIV-1 gp120 that activated phagocytes preferentially through FPRL1 and down-regulated the expression and function of two chemokine receptors, CCR5 and CXCR4, which act as key fusion cofactors for HIV-1, through a protein kinase C-dependent pathway (22).

Our findings indicate the patho-physiological significance of the interaction between HIV-1 and phagocytic leukocytes. It has been reported that monocytes isolated from HIV-1-infected patients responded poorly to a variety of chemoattractants, including fMLF (13), in vitro. Several neutrophil functions are also impaired in HIV-infected patients, including chemotaxis, phagocytosis, oxidative metabolism, and killing of bacterial and fungal pathogens (23-28). However, the reason for reduced phagocyte function in such patients is not clear. We have found that recombinant soluble gp41 and gp120 of HIV-1 are able to potently down-regulate the expression and function of the receptors for a variety of chemotactic factors such as FMLF and a number of chemokines on monocytes, but not on neutrophils $(11,12)$. Soluble gp120 has been shown to also down-regulate the surface expression of the receptor for activated complement component C (C5a) on normal human monocytes (29). Mechanistic studies have shown that soluble gp120 and gp41 down-regulated chemoattractant receptors on monocytes by activating a protein kinase C (PKC)-mediated signaling pathway, a process resembling receptor "heterologous desensitization" $(11,12)$.

Our efforts to identify the structural basis for the effect of HIV-1 envelope proteins have yielded several peptide domains, such as T21/DP 107 and T20/DP178, that are selective activators for the $\mathrm{AMLF}$ receptors FPR and/or FPRL1 $(14,17,22)$. These findings, together with our present observation on the N36 peptide domain in gp41, suggest that HIV-1 envelope proteins contain multiple fragments that may potentially interact with cellular receptors, thus affecting the immune responses. Although the accessibility of such a HIV-1 envelope domain(s) in vivo to host immune cells remains to be determined, it has been reported that antibodies recognizing various epitopes in envelope proteins, such as T20/DP178 and T21/DP107, appear at early stages of HIV-1 infection (30-32). Therefore, even though formylated peptide receptors FPR and FPRL 1 have not been reported as coreceptors used by HIV-1 for fusion, they may participate in the initial stimulation of the host innate defense responses seen in AIDS patients followed by a progressive inhibition of phagocytic cell function possibly due to desensitization of cell surface receptors. Recently, Munoz et al. (33) reported that superoxide production by neutrophils isolated from HIV-1-positive patients in response to stimulants of FC receptor or PKC was significantly suppressed. Pretreatment of neutrophils, isolated from healthy donors, with a synthetic V2 domain derived 
A

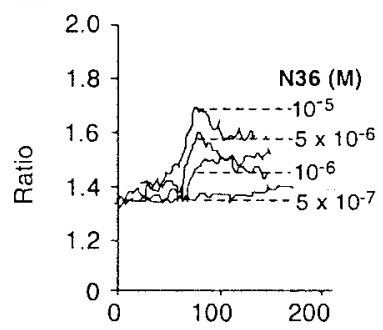

D

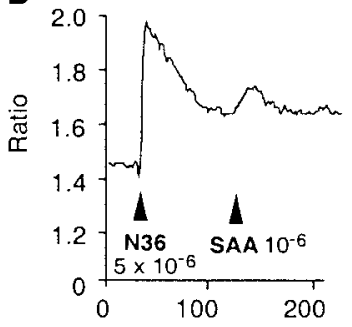

B
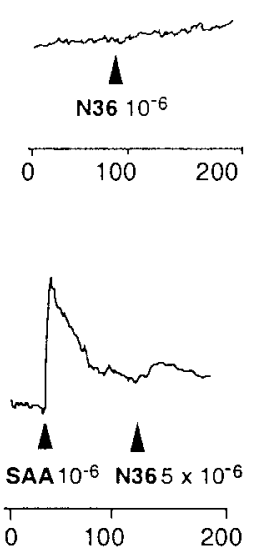

C

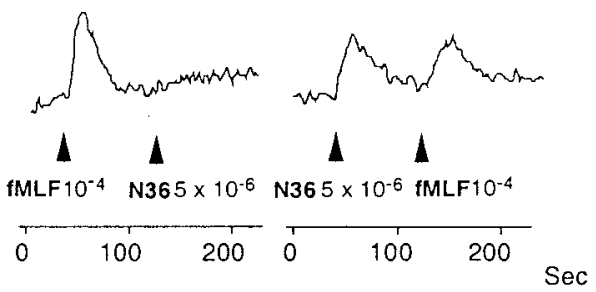

E

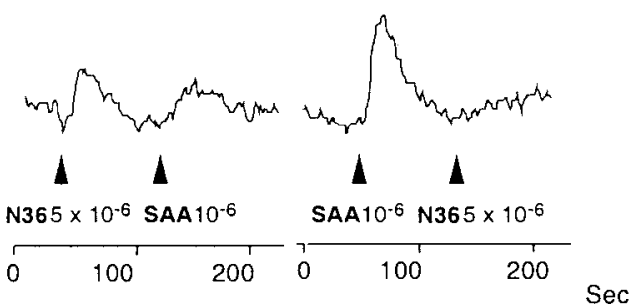

FIG. 5. Calcium mobilization induced by $N 36$ peptide in FPRL1/293 cells and attenuation by fMLF or SAA. Cells were loaded with Fura-2. (A) FPRL 1/293 cells were stimulated with different concentrations of N36 peptide. (B) N36 peptide did not induce calcium flux in ETFR cells. (C) Sequential stimulation of FPRL1/293 cells with N36 peptide and fMLF or vice versa. (D and E) Cross-desensitization of calcium mobilization between N36 and SAA in human monocytes (D) and FPRL1/293 cells (E).

from the HIV-1 SF2 strain envelope gp120 inhibited superoxide production of these cells in response to FC receptor stimulants. Further studies showed that the V2 peptide reduced the phosphorylation of two cellular proteins, but increased the level of a third phosphorylated protein. These results may provide a basis for the observations that neutrophils from HIV-1-infected subjects exhibit "primed" phenotypes with reduced response to further stimulation $(25,28,34,35)$. I nterestingly, while neutrophils are resistant to HIV-1 infection, eosinophils express HIV-1 coreceptors and are susceptible to viral infection (36). Eosinophils also express fMLF receptors FPR and FPRL1 (37). Further studies are required to elucidate the activity of HIV-1 envelope proteins and their domains on eosinophils and to determine whether these molecules contribute to the viral interference. The identification of domains in HIV-1 envelope proteins that activate phagocyte receptors may facilitate the understanding of the pathogenesis of AIDS and the development of immunoregulatory agents.

\section{ACKNOWLEDGMENTS}

The authors thank Dr. J . J . Oppenheim and P. M. Murphy, for reviewing the manuscript; Drs. P. M. Murphy and J. Gao $(\mathrm{NIH}$, Bethesda, MD), for providing FPRL1/293 cells; Drs. H. Ali and R. Snyderman (Duke University, Durham, NC), for providing ETFR cells; Dr. M. Lu (Cornell University Medical College, New York, NY), for the recombinant N36(L6)C34; and Dr. P. Kim (Massachusetts Institute of Technology, Cambridge, MA), for C34 peptide. The secretarial assistance of $\mathrm{C}$. Fogle is gratefully acknowledged. This project has been funded in whole or in part with federal funds from the National Cancer Institute, National Institutes of Health, under Contract No. NO1-CO-56000.

\section{REFERENCES}

1. Chan, D. C., and Kim, P. S., HIV entry and its inhibition. Cell 93, 681- 684, 1998.

2. Moore, J . P., J ameson, B. A., Wess, R. A., and Sattentau, Q. J ., The HIV-cell fusion reaction. In "Viral Fusion Mechanisms" (J . Bentz, Ed.), pp. 233-289, CRC Press, Boca Raton, FL, 1993.

3. J iang, S., Lin, K., Strick, N., and Neurath, A. R., HIV-1 inhibition by a peptide. Nature 365, 113, 1993.

4. Wild, C. T., Shugars, D. C., Greewell, T. K., McDanal, C. B., and Matthews, T.J ., Peptides corresponding to a predictive $\alpha$-helical domain of human immunodeficiency virus type $1 \mathrm{gp} 41$ are potent inhibitors of virus infection. Proc. Natl. Acad. Sci. USA 91, 9770-9774, 1994.

5. Wild, C. T., Oas, T., McDanal, C. B., Bolognesi, D., and Matthews, T. J ., A synthetic peptide inhibitor of human immunodeficiency virus replication: Correlation between solution structure and viral inhibition. Proc. Natl. Acad. Sci. USA 89, 1053710541, 1992.

6. Lu, M., Blackow, S. C., and Kim, P. S., A trimeric structural domain of the HIV-1 transmembrane glycoprotein. Nat. Struct. Biol. 2, 1075-1082, 1995.

7. Lu, M., and Kim, P. S., A trimeric structural subdomain of the HIV-1 transmembrane glycoprotein. J . Biomol. Struct. Dyn. 15, 465-471, 1997.

8. Chan, D. C., Fass, D., Berger, J. M., and Kim, P. S., Core structure of gp41 from the HIV-envelope glycoprotein. Cell 89, 263-273, 1997.

9. Tan, K., Liu, J ., Wang, J ., Shen, S., and Lu, M., Atomic structure of a thermostable subdomain of HIV-1 gp41. Proc. Natl. Acad. Sci. USA 94, 12303-12308, 1997. 
10. Weissenhorn, W., Dessen, A., Harrison, S. C., Skehel, J . J ., and Wiley, D. C., Atomic structure of the ectodomain from HIV-1 gp41. Nature 387, 426-430, 1997.

11. Ueda, H., Howard, O. M. Z., Grimm, M. C., Su, S. B., Gong, W., Evans, G., Ruscetti, F. W., Oppenheim, J . J ., and Wang, J . M., HIV-1 gp41 is a potent inhibitor of chemoattractant receptor expression and function in monocytes. J . Clin. Invest. 102, 804812, 1998.

12. Wang, J . M., U eda, H., H oward, O. M. Z., Grimm, M. C., Chertov, O., Gong, X., Gong, W., Resau, J . H., Broder, C. C., Arthur, L. O., Ruscetti, F. W., and Oppenheim, J . J ., HIV-1 envelope gp120 inhibits monocyte response to chemokines through CD4 signaldependent chemokine receptor down-regulation. J . Immunol. 161, 4309-4317, 1998.

13. Smith, P. D., Ohura, K., Masur, H., Lane, H. C., Fauci, A. S., and Wahl, S. M., Monocyte function in the acquired immune deficiency syndrome. Defective chemotaxis. J . Clin. I nvest. 74, 21212128, 1984.

14. Su, S. B., Gong, W., Gao, J ., Shen, W., Grimm, M. C., Deng, X., Murphy, P. M., Oppenheim, J . J ., and Wang, J . M., T20/DP178, an ectodomain peptide of human immunodeficiency virus type 1 gp41, is an activator of human phagocyte $\mathrm{N}$-formyl peptide re ceptor. Blood 93, 3885-3892, 1999.

15. Murphy, P. M., The $\mathrm{N}$-formyl peptide chemotactic receptors. In "Chemoattractant Ligands and Their Receptors" (R. Horuk, Ed.), pp. 269-299, CRC Press, Boca Raton, FL, 1996.

16. Prossnitz, E. R., and Ye, R. D., The N-formyl peptide receptor: a model for the study of chemoattractant receptor structure and function. Pharmacol. Ther. 74, 73-102, 1997.

17. Su, S. B., Gao, J., Gong, W., Dunlop, N. M., Murphy, P. M., Oppenheim, J.J., and Wang, J. M., T21/DP107, a synthetic leucine zipper-like domain of the HIV-1 envelope gp41, attracts and activates human phagocytes by using $\mathrm{G}$ protein-coupled formal peptide receptors. J . I mmunol. 162, 5924-5930, 1999.

18. Oppenheim, J.J ., Zachariae, C. O., Mukaida, N., and Matsushima, K., Properties of the novel proinflammatory supergene "intercrine" cytokine family. Annu. Rev. Immunol. 9, 617-648, 1991.

19. Su, S. B., Gong, W., Gao, J ., Shen, W., Murphy, P. M., Oppenheim, J. J ., and Wang, J. M., A seven-transmembrane, G-protein-coupled receptor, FPRL 1, mediates the chemotactic activity of serum amyloid A for human phagocytic cells. J . Exp. Med. 189, 395- 402, 1999.

20. Badolato, R., J ohnston, J . A., Wang, J . M., McVicar, D., Xu, L. L., Oppenheim, J . J ., and Kelvin, D. J., Serum amyloid A induces calcium mobilization and chemotaxis of human monocytes by activating a pertussis toxin-sensitive signaling pathway. J . I mmunol. 155, 4004-4010, 1995.

21. Badolato, R., Wang, J . M., Murphy, P. M., Lloyd, A. R., Michiel, D. F., Bausserman, L. L., Kelvin, D. J ., and Oppenheim, J . J ., Serum amyloid $A$ is a chemoattractant: induction of migration, adhesion, and tissue infiltration of monocytes and polymorphonuclear leukocytes. J . Exp. Med. 180, 203-209, 1994.

22. Deng, X., Ueda, H., Su, S. B., Gong, W., Dunlop, N. M., Gao, J ., Murphy, P. M., and Wang, J. M., A synthetic peptide derived from HIV-1 gp120 down-regulates the expression and function of chemokine receptors CCR5 and CXCR4 in monocytes by activating the seven-transmembrane $G$ protein-coupled receptor FPRL 1/LXA4R. Blood 94, 1165-1673, 1999.

23. Abramson, J. S., and Wheeler, J. G., Virus-induced neutrophil dysfunction: Role in the pathogenesis of bacterial infections. Pediatr. Infect. Dis. J . 13, 643- 652, 1994.
24. Ellis, M., Gupta, S., Galant, S., Hakim, S., VandeVen, C., Toy, C., and Cairo, M. S., Impaired neutrophil function in patients with AIDS or AIDS-related complex: A comprehensive evaluation. J . Infect. Dis. 158, 1268-1276, 1988.

25. Meddows-Taylor, S., Martin, D. J ., and Tiemessen, C. T., Reduced expression of interleukin-8 receptors $A$ and $B$ on polymorphonuclear neutrophils from persons with human immunodeficiency virus type 1 disease and pulmonary tuberculosis. J . I nfect. Dis. 177, 921-930, 1998.

26. Valone, F. H., Payan, D. G., Abrams, D. I., and Goetzl, E. J ., Defective polymorphonuclear leukocyte chemotaxis in homosexual men with persistent Iymph node syndrome. J. Infect. Dis. 150, 267-271, 1984.

27. Pitrak, D. L., Bak P. M., DeMarais P., Novak, R. M., and Andersen, B. R., Depressed neutrophils superoxide production in human immunodeficiency virus infection. J. Infect. Dis. 167, 1406-1410, 1993.

28. Wenisch, C., Parschalk, B., Zedwitz-Liebenstein, K., Graninger, W., and Rieger, A. Dysregulation of the polymorphonuclear leukocyte-Candida spp. interaction in HIV-positive patients. AIDS 10, 983-987, 1996.

29. Wahl, S. M., Allen, J . B., Gartner, S., Orenstein, J . M., Popovic, M., Chenoweth, D. E., Arthur, L. O., Farrar, W. L., and Wahl, L. M., HIV-1 and its envelope glycoprotein down-regulate che motactic ligand receptors and chemotactic function of peripheral blood monocytes. J . I mmunol. 142, 3553-3559, 1989.

30. Gelderblom, H. R., Hausmann, E. H. S., Ozel, M., Pauli, G., and Koch, M. A., Fine structure of human immunodeficiency virus (HIV) and immunolocalization of structural proteins. Virology 156, 171-176, 1987.

31. Nara, P. L., Garrity, R. R., and Goudsmit, J ., Neutralization of HIV-1: A paradox of humoral proportions. FASEB J . 5, 24372455, 1991.

32. Hattori, T., Komoda, H., Pahwa, S., Tateyama, M., Zhang, X., Xu, Y., Oguma, S., Tamamura, H., Fujii, N., Fukutake, K., and Uchiyama, T., Decline of anti-DP107 antibody associated with clinical progression. AIDS 12, 1557-1559, 1998.

33. Munoz, J . F., Salmen, S., Berrueta, L. R., Carlos, M. P., Cova, J . A., Donis, J . H., Hernandez, M. R., and Torres. J . V., Effect of human immunodeficiency virus type 1 on intracellular activation and superoxide production by neutrophils. J. Infect. Dis. 180, 206-210, 1999.

34. Pitrak, D. L., Tsai, H. C., Mullane, K. M., Sutton, S. H., and Stevens, P., Accelerated neutrophil apoptosis in the acquired immunodeficiency syndrome. J . Clin. Invest. 98, 2714-2719, 1996.

35. Shalekoff, S., Tiemessen, C. T., Gray, C., M., and Martin, D. J ., Depressed phagocytosis and oxidative burst in polymorphonuclear leukocytes from individuals with pulmonary tuberculosis with or without human immunodeficiency virus type 1 infection. Clin. Diag. Lab. Immunol. 5, 41-44, 1998.

36. Chelucci, C., Casella, I., Federico, M., Testa, U., Macioce, G., Pelosi, E., Gueriero, R., Mariani, G., Giampaolo, A., Hassan, H. J., and Peschle, C., Lineage-specific expression of human immunodeficiency virus (HIV) receptor/coreceptors in differentiating hematopoietic precursors: Correlation with susceptibility to T- and M-tropic HIV and chemokine-mediated HIV resistance. Blood 94, 1590-1600, 1999.

37. Gerard, N. P., Bao, L., Xiao, P. H., Eddy, R. L. J r., Shows, T. B., and Gerard, C., Human chemotaxis receptor genes cluster at 19q13.3-13.4. Characterization of the human C5a receptor gene. Biochemistry 32, 1243-1250, 1993. 